\title{
特別発表
}

\section{MACROERGONOMICS, THE THIRD GENERATION OF HUMAN FACTORS}

\author{
Hal W. Hendrick
}

Human Factors Department

Institute of Safety and Systems Management

University of Southern California

Los Angeles, CA 90089-0021

USA

\begin{abstract}
Human factors is conceptualized as having had two generations of development. The first generation dealt with the ergonomic design of specific jobs and work stations. The focus of person-machine technology research was on human physical and perceptual characteristics. The second generation, driven by the microelectronics technology explosion of the late 60's and 70's, focused on the cognitive nature of work as reflected in system design. Both first and second generation activities remain important and are continuing. Both primarily deal with person-machine systems at the individual and team, or microergonomic level. The emerging third generation is concerned with the interface of technology with the organization at the macroergonomic level, and represents a top down approach to system design. This third generation is being driven primarily by the organizational design constraints of automation and the concomitant changes in technology, and in the demographic characteristics and values of the work forces of industrialized nations. These changes are discussed along with the nature of macroergonomics, and the third generation challanges for the human factors profession.
\end{abstract}




\title{
MACROERGONOMICS, THE THIRD GENERATION OF HUMAN FACTORS
}

\author{
Hal W. Hendrick \\ University of Southern California
}

Human factors (or ergonomics) is a science, a design philosophy, and, of course, a profession. Historically, human factors had its origin in the aircraft industry in the United States, and in the ergonomic design of factory work stations in Europe and Japan in the 1940's and early 50's. From this begining, our profession spread to consumer products, all forms of transportation systems, and a progressively broadening number of industries and new technology applications. This first generation of human factors tended to focus on the design of specific jobs, work groups, and related person-machine interfaces. Typically, in system design, the operations to be required of the system to accomplish its purposes were identified. These operations, in turn, were analyzed to identify the specific functions that comprise them. The human factors specialist often came into the design process at this point and, based on his professional knowledge of human performance capabilities and limitation, assisted in allocating these functions to humans or machines. From this point in the process, the human factors specialist's knowledge of person-machine technology was applied to designing specific jobs, integrating jobs into work groups, and then designing specific person-machine interfaces including controls, displays, work space arrangements, and work environments. Much of the human factors research was focused on anthropometry, perceptual characteristics, and other human physical characteristics in terms of their implications for the hardware design of person-machine interfaces. This continues to be an extremely importent ongoing aspect of the science and practice of human factors.

The second generation of human factors begain as, increasingly, we emphasized the cognitive nature of work, as reflected in systems design. Much of this new shift in emphasis was driven by the new technology of the late 1960's and 70's. In particular, the development of the silicon chip and the resulting work on computer systems. As we begain work on computers, the way that people think and process data became increasingly important to system design. Software structures, as well as screen layouts and menu design are important areas where the application of knowledge about how people process and use information has made an impact on how "user-friendly" or "easy to use" a system is. This focus on the cognitive human has influenced the design of many and diverse types of products and systems. As human factors specialists, we can take pride in the influence this second generation of our work has had, and will continue to have on improving system operability and productivity. As but one example, recent studies have shown that human factors redesign of computer workstations improves productivity by ten to fifteen percent, and redesign of software results in an even more dramatic improvement of around twenty-five percent ${ }^{1}$.

One impact of the progressivly increasing automation of factory and office systems has been a concurrent increase in our awareness of the impacts of technology on organizational systems. Conceptually, we have begun to realize that it is entirely possible to do an outstanding job of microergonomically designing a system's components, modules and subsystems, yet fail to reach relevant systems effectiveness goals because of inattention to the macroergonomic design of the system. Although applied within a systems framework, most of 
the work of the first two "generations" of our profession was focused on the design of specific jobs, work groups, and related person-machine interfaces. In short, these human factors efforts have been at the individual, team, or at best, subsystem level. These human factors efforts thus have represented applications at the microergonomic level. The emerging third generation of human factors is focused at the macroergonomic or overall sociotechnical system level. The concern of macroergonomics begins with an assessment of the organization from the top down, using a sociotechnical system approach to organizational and system design. The notion here is that one cannot effectively design specific atomistic components of an organizational system without first making scientific and reasoned decisions about the design of the overall organization, including how it is to be managed. Questions first must be answered concerning the optimal degree of complexity, centralization, and formalization that should be ergonomically designed into the organization's structure. Once these organizational design decisions are made, then one can begin to intellegently design specific subsystems, jobs, and work stations that will be compatable with the overall macrodesign of the system. For example, until we know the optimal degree of formalization and centralization, we will not know what kinds of decisions will have to be made by employees or where in the system hierarchy specific kinds of decisions will be made. We thus can not make decisions about the design of information and decision support systems and related operator positions, tasks, and person-machine interfaces. If we go ahead and design our support systems and individual jobs without first making these macroergonomic design decisions, we will be forced to live with the constraints this imposes on overall organizational design, and the result is likely to be suboptimal. In short, we end up with the microergonomic tail wagging the macroergonomic dog.

Although a number of identifiable factors have contributed to the emergence of what I have labled "macroergonomics", and Dr. Susan Dray of Honeywell, Inc. referres to as the "third generation" of human factors, I would like to cite what appear to be the two major causes. These are (a) new technology and organizational automation, and (b) demographic and psycho-social work force changes in industrialized countries.

a. New technology. Since the development of the silicon chip, we have seen an exponential explosion in the development and application of new technology. This has been particularly true in the development of new materials, such as fiber optics, and computer-based automated systems. The development of this new technology has created human factors challanges in terms of how best to exploit technological innovations in person-machine systems. In a sense, it also has led to a greater "hard wiring" of our sociotechnical systems with concomitant restraints on organizational design. In general, as we progressively automate our sociotechnical systems, we also progressively restrain their structural characteristics. In part, we are able to overcome some of this constraint by creative design of greater flexibility into automated personmachine systems, but still they lack the flexibility of more manual systems in terms of organizational design. It is this dual question of how best to exploit this new, and rapidly changing technology, and how to ensure that the resultant constraints on organizational design do not result in suboptimal functioning that have created the need for a macroergonomic approach to the ergonomic design of sociotechnical systems. 
b. Work force changes. There are two major changes occuring in work forces to a greater or lessor degree in most industrialized countries. The first of these is demographic in nature, and the second is psycho-social. The demographic change that is impacting on the ergonomic design of our sociotechnical organizations is the progressive "greying" of the work force. The psycho-social change is the increase in the cognitive complexity of the work force and the related shifts in woker values and attitudes towards work, organizational structures, and the legitimate roll of managers.

The greying of the work force is the result in the tremendous advances in medicine and health care, and the "baby boom" that occured in most industrialized countries following World War II. The baby boom population now is moving through the work force. As this demographic bulge ages and remains healthy and productive, the entire work force ages. In the United States, the work force presently is aging at a rate of one-half year per year. In the 1990's, our work force will reach a point where it is a full decade older on the average than it was in the late 1960's. As a result, the average worker is more experienced, skilled and mature, and expects this greater skill and maturity to be recognized in his or her job. Ergonomically, this means that the worker expects the design of the organization to be less centralized and formalized; that the worker, rather than management will make most of the tactical decisions concerning his or her work; That management will show respect for the worker as a mature adult and more fully utilize the worker's psychological and intellectual capacities, and not just his or her physical skills. The result is an organizational design and management system that facilitates participative decision-making, at least for the tactical decisions of the operation. From a psycho-social perspective, the tremendous increase in the quality and availability of knowledge through the transportation and communications systems, and related affluence of the work force since World War II has resulted in a more cognitively complex work force. As the research literature has shown, as persons conceptual complexity increases, they become less authoritarian, more open minded, have less need for structure and rigid rules, have greater tolerance for ambiguity, and become more effective problem solvers and decision-makers 2.3 . This tends to be reflected in a dynamic, rather than static view of the world, more openness to change and in a different set of attitudes towards work and organizational design. As Yankelovich and his colleagues in the United States have documented; the workers who have grown up in the U.S. since World War II have a value system that is so different from that of the past, that these younger workers can be thought of as a "new breed". In particular, he notes that they expect to have quality social relationships at work, and to be treated with respect by their superiors as skilled adults. 4 Operationally, this translates into greater participation in decision-making, less centralized and formalized organizational structures, and a less authoritarian management. As may be noted, both the psycho-social and demographic trends cited herein lead to the same basic conclusions regarding organizational design. One of the major current challanges for us as human factors specialists is how to meet these expectations by modifying traditional bureaucratic structures, yet retain the advantages that have made these structures so successful in the past. A related challenge will be to meet these worker expectations while, at the same time, being responsive to the type of industry, technology, and environmental demands that characterize a particular organization. The other 
side of this challange is how to design our automated systems so as to be responsive to these comparitively new worker values and attitudes towards sociotechnical systems, work, and the quality of work life.

One impact, as well as reflection of this emerging "third generation" of human factors has been the creation of the Organizational Design and Management Technical Group within the Human Factors Society in the United States, and the current efforts to organize an international Technical Group under sponsorship of the International Ergonomics Association in this area. Both of these professional activities reflect a need for developing a network of human factors specialists in the macroergonomics field. The purposes of these networks include information exchange and the synergistic development of new research ideas and new methodology. Macroergonomics is still in its infant stage of development. Yet the exponential explositon of new technology is creating immediate demands for macroergonomic data and the application of macroergonomic information and principles. To meet this demand, we as a profession will have to pool our ideas, methods, and information; we will have do develop collaborative and coordinated research projects; we will have to try out one anothers methodological innovations; and we will have to interface with other disciplines, such as Industrial and Organizational Psychology. Through this kind of professional collaboration we can achieve the kind of synergy that is necessary to have a real impact on improving our organizations and, indeed, society. I firmly believe that this third generation of our profession offers us the opportunity to exponentially increase our ability to design for a more productive and humane world. Whether or not we will have this kind of exponential impact will depend, in my opinion, on our skill at organizing for, and synergistically collaborating with one another in advancing the science and art of macroergonomics.

\section{REFERENCES}

1. World Conference on Ergonomics, Los Angeles, California, September 25, 1985. Proceedings in press.

2. Harvey, O.J., Hunt, D.E., and Schroder, H.M.(1961). Conceptual systems and personality organization. New York: Wiley.

3. Hendrick, H.W. (1979). Differences in group problem solving as a function of cognitive complexity. Journal of Applied Psychology. 64, 518-525.

4. Yankelovich, D. (1978, May). The new psychological contracts at work. Psychology Today. 46-50. 